\section{WHY ARE THE RESULTS REPORTED FROM THIS CENTER INCONSISTANT WITH THE GENERAL EXPERIENCE OF 4000 IMPLANTS AND 10 YEARS OF FOLLOW-UP?}

\section{To the Editor:}

The article previously published in the Journal ${ }^{1}$ presents a series of cases of the Shelhigh 2000C (Shelhigh Inc, Union, NJ) aortic valve conduit for the Bentall procedure. Shelhigh Inc appreciates Carrel and colleagues, 1 study of the device and their appreciation for the device's benefits to patients. Although Shelhigh Inc is interested in getting fair clinical feedback on its products, I believe the article was misleading.

Aspects of the article beg important questions, and, in my view, their article lacks clinical context and historical accuracy. I'd like to offer your readers (1) a clearer account of the company's communication with Berne regarding the devices, particularly with regard to surgical technique; (2) a wider clinical perspective on the device; and (3) questions that the article simply begs for an answer.

Shelhigh Inc was not remiss in the close surveillance of its products. Before this publication, the company had not seen most of the cases in the article. Carrel and colleagues did not mention that despite requests by Shelhigh Inc, they never submitted full case documentation. Those reports were particularly

\footnotetext{
The Editor welcomes submissions for possible publication in the Letters to the Editor section that consist of commentary on an article published in the Journal or other relevant issues. Authors should: - Include no more than 500 words of text, three authors, and five references. - Type with double-spacing. - See http://jtcs.ctsnetjournals.org/misc/ifora.shtml for detailed submission instructions. - Submit the letter electronically via jtcvs.editorialmanager.com. Letters commenting on an article published in the JTCVS will be considered if they are received within 6 weeks of the time the article was published. Authors of the article being commented on will be given an opportunity of offer a timely response ( 2 weeks) to the letter. Authors of letters will be notified that the letter has been received. Unpublished letters cannot be returned.
}

needed in one instance in which the company wanted properly to report an adverse event to Swiss medics. If Carrel and colleagues are positive that Shelhigh Inc's feedback was inadequate, they should have sent in more information from which to adjust the clinical understanding of the product. Regrettably, even this article fails to provide a complete clinical picture.

Regardless, as Shelhigh Inc noted to Carrel and colleagues in the discussion of one case, bleeding at the suture line at the time of operation does not yield best results: A false aneurysm can occur. Shelhigh Inc admonished them to make sure the anastomosis is completely "ddry.', Pledgets are one solution; tighter suture "bites" are another. The literature documents this common issue and suggests various solutions.

Problems associated with aortic reconstruction are mainly caused by the laxity of aortic tissues involved by dissection and the difficulties in obtaining sufficient mechanical strength and hemostasis in the reconstruction. ${ }^{2}$ In the case of hematoma and false aneurysm, the company believes they were likely caused by errors in technique. But that is only half of the solution: the clinical issues presented by the patient (eg, age, thickness of the aorta, and preexisting disease of the aorta). Shelhigh Inc products are often used in sick cohorts of patients ${ }^{3}$ (eg, endocarditis, patients in whom anticoagulation must be obviated), and great surgical care must always be part of the overall clinical solution.

Looking further afield into the entire body of 2000C clinical experience, the article's cases seem specific to the site. On analyzing the clinical data from more than 4000 implants of the conduit over 10 years, the reported adverse event rate is $0.3 \%$. These events are mainly from endocarditis. Carrel and colleagues' accusation of a device "dissolving" and tissue degeneration or calcification were never reported, and they never sent Shelhigh Inc an explant of dissolved tissue. But, even if all of the cases mentioned in their article were included in adverse data, the event rate increases to $0.5 \%$. This is a very low event rate when compared with homograft and synthetic aortic root replacement options $(2 \%-7 \%)$.

At no point does Shelhigh Inc put reputational risk ahead of patient safety. I would like to inform readers that that is precisely why Shelhigh Inc refused to implement a Food and Drug Administration (FDA)-suggested recall: No empirical evidence suggested anything was wrong with the devices, and despite unfounded FDA concerns, explanting functioning devices would present more risk to patients than the devices themselves. If the FDA had any evidence of sterility or structural issues for the devices, a recall would have been mandated by the agency, I assure you. Looking back, the decision was the right one.

European authorities agreed with this view. In late 2007, the 25 member nations of the European Union exonerated Shelhigh Inc and its devices, stating it found none of the FDA deficiencies alleged. And rightly so-the FDA never substantiated its claims. As the recent tomato/ salmonella scare in the United States suggests, despite best intentions, government agencies can sometimes miss the mark.

Finally, I believe the article begs several questions, which I'd like to ask:

Why weren't these cases all reported to the company?

Why were no deaths reported to the company?

Why were these issues specific to the site?

Why do the authors publish on 7 cases, when they only have partial data on 4 of them?

If the results were so negative, why was the product used for several years and also reimplanted in 2 patients?

Why weren't the warnings regarding technique heeded? 


\section{Shlomo Gabbay, MD \\ University Medical and Dentistry of NJ, Department of Cardiothoracic Surgery, New Jersey Medical School}

Newark, NJ

\begin{abstract}
References
1. Carrel TP, Schoenhoff FS, Schmidli J, Stalder M, Eckstein FS, Englberger L. Deleterious outcome of No-React-treated stentless valved conduits after aortic root replacement: why were warnings ignored? J Thorac Cardiovasc Surg. 2008;136:52-7.

2. Rignano A, Keller GC, Carmo M, Anguissola GB Settembrini PG. A new approach for proximal anastomosis in type 'A' acute aortic dissection: prosthesis eversion. Ann Thorac Surg. 2003;76:949-51.

3. Musci M, Siniawski H, Pasic M, Weng $Y$ Loforte A, Kosky S, et al. Surgical therapy in patients with active infective endocarditis: sevenyear single centre experience in a subgroup of 255 patients treated with the Shelhigh stentless bioprosthesis. Eur J Cardiothoracic Surg. 2008;34:410-7. Epub 2008 Jun 24.
\end{abstract}

doi:10.1016/j.jtcvs.2008.08.067

\section{Reply to the Editor:}

Annescis, mi fili, quantilla sapientia mundus regatur?

[Do you not know, my son, how little wisdom rules the world?]

We thank Dr Gabbay for his letter to the editor regarding our recent article, "Deleterious Outcome of No-ReactTreated Stentless Valved Conduits after Aortic Root Replacement: Why Were Warnings Ignored?" We understand that Dr Gabbay is under considerable pressure because he is not only chief scientific officer of Shelhigh Inc (Union, NJ) but also founder and therefore directly dependent on the economic well-being of the company. We believe it is human nature that $\mathrm{Dr}$ Gabbay is biased in his perception of the events surrounding the aortic conduit NR-2000C (Shelhigh Inc) and other products. We, as representatives of a medical institution, have no interest in accusing Dr Gabbay, but we merely worry about the outcome observed in some of our patients after having used products from Shelhigh Inc.

In our department within the Academic Center for Cardiac Surgery Berne-Basel $(\sim 1800$ cardiac cases per year), surgery of the thoracic aorta accounts for approximately $15 \%$ of the overall surgical volume. This is due to the high prevalence of aortic aneurysms in the region and a high rate of referrals. We perform approximately 200 to 220 thoracic aortic procedures per year. We most recently published our results after surgery on the thoracic aorta, and these are consistent with contemporary literature. ${ }^{2-4}$ All patients described in our article ${ }^{1}$ were operated on by 3 senior staff surgeons (T.C., F.E., J.S.), each of whom has approximately 20 years experience in the field. None of them were ever faced with a pathology like the one observed with the NR-2000C aortic tube valved conduit.

As Dr Gabbay pointed out, a significant percentage of these patients were high risk: A few of them underwent repeat surgery because of endocarditis. We hesitated a long time to attribute these catastrophic findings to the Shelhigh device, but as the picture became more consistent, we were able to rule out other causes of failure, including surgical technique. Our suspicion that something was wrong with the device was emphasized by similar observations with other Shelhigh products (eg, the bovine internal thoracic artery used as peripheral bypass conduit or exceptionally as coronary bypass conduit).

We are concerned about the fact that Dr Gabbay refuses to acknowledge findings as demonstrated in our article. ${ }^{1}$ We had several meetings with Dr Gabbay but it was never possible to bring our concerns to the point.

The fact that Dr Gabbay talks about salmonella and tomatoes when we report on patients who may unexpectedly die during follow-up or on the operating table supports our decision to not further discuss these matters with the company itself. We send all explanted material to our in-house certified pathology and microbiology department. Although we had severe concerns with the management of the company after several visits in Union, New Jersey, we were terrified after reading the Food and Drug Administration (FDA) document: "Your firm's [Shelhigh] Medical Device Reporting Procedure (Document No. 020047) is deficient in that: (1) The procedure lacks a standardized review process for determining when an event meets the criteria for submitting an MDR report. (2) There are no procedures for documentation and record-keeping requirements to determine if information was evaluated to determine if an event was reportable and that all events and subsequent information are submitted within appropriate timeframes., 5

Unlike Dr Gabbay, we were shocked to learn about additional, repeated warning letters issued by the FDA (April 26, 2000, December 14, 2005), because we were not informed by the company about ongoing problems and at the time they were brought to our attention, we had already implanted the NR-2000C in more than 100 patients. We assume that the majority of the readers of the Journal would be as worried as we are to learn about such a critical situation. Citation of the FDA: "The environmental controls and processes used to manufacture and test devices within your facility can compromise the sterility and safety of these products, and there is therefore a reasonable probability that use of such products will cause serious adverse health consequences or death.,"6

We can assure Dr Gabbay and the readership of the Journal that these patients receive the closest and most optimal follow-up possible. However, we are unable within this short letter to provide detailed in-hospital data and follow-up on these patients with more than 1500 single items per patient, including repeated imaging and extensive laboratory work. Dr Gabbay insists that the issue is site specific, and indeed that was one of the reasons we hesitated to issue a formal complaint. We do think at this point that the circumstances of a high aortic caseload together with an unusual follow-up of almost $100 \%$ may have helped to 